\title{
Sobre compendios y ficciones en el pensamiento juvenil de Leibniz
}

\author{
FEDERICO RAFFO QUINTANA \\ Universidad Nacional de Quilmes \\ Consejo Nacional de Investigaciones Científicas y Técnicas \\ Universidad Católica Argentina
}

DOI: $10.36446 /$ rlf2020203

Resumen: En este trabajo buscaré dilucidar la noción de ficción en el pensamiento parisino de Leibniz. Veremos que esta noción se esclarece si tenemos en cuenta, como marco teórico, la concepción leibniziana del conocimiento simbólico. La conexión entre la concepción de las ficciones y la del pensamiento simbólico se observa por el hecho de que Leibniz pensó las ficciones como abreviaturas o compendios del hablar, pensar, descubrir y demostrar. Teniendo en cuenta este hilo conductor, veremos que las ficciones fueron pensadas como nociones ciegas (no hay una idea que les corresponda), confusas (tenemos un conocimiento vago del significado de las expresiones), analógicas (las empleamos como si designaran entidades posibles) y creativas (el geómetra debe introducirlas al modo de una suposición).

Palabras clave: ficciones, caracteres, conocimiento ciego, analogía. 


\title{
On Compendia and Fictions in Leibniz's Youth Thought
}

\begin{abstract}
In this paper I will try to elucidate the notion of fiction suggested by Leibniz in his Parisian period.This notion is clarified if we take into account the Leibnizian conception of symbolic knowledge as theoretical framework. The connection between Leibniz's conception of fictions and that of symbolic thought is observed in the fact that he conceived fictions as abbreviations or compendia of speaking, thinking, discovering and demonstrating. With this in mind, we will see that fictions were thought as blind (there is no idea that corresponds to them), confused (we have a vague knowledge of the meaning of the expressions), analogous (we employ them as if they designate possible entities) and creative (the geometer must introduce them as suppositions) notions.
\end{abstract}

Keywords: fictions, characters, blind knowledge, analogy.

\section{Introducción}

Como es sabido, el desarrollo de Leibniz en el terreno de la ma-
temática infinita fue muy significativo, tanto en su propio contexto histórico como para la posteridad. Hace algunas décadas, gracias a la constante publicación de los escritos matemáticos de Leibniz llevada a cabo en el marco de la edición crítica de la Berlin-Brandenburgischen Akademie der Wissenschaften y la Akademie der Wissenschaften zu Göttingen, se han multiplicado los estudios sobre los escritos matemáticos de Leibniz durante su estadía en París (1672-1676). En general se suelen destacar no solamente sus avances en diversos terrenos, como, por ejemplo, en suma de series infinitas ( $A$ VII 3 ), en cuadraturas ( $A$ VII 6 ) y en otros problemas de matemática infinitesimal ( $A$ VII 4 y 5 ), sino también el hecho de que, en estos años de juventud, Leibniz ya había recurrido al empleo de ficciones, lo que muestra que no fue algo exclusivo de su pensamiento de madurez (señalo solamente dos textos actuales que examinan esta cuestión con posiciones bastante diferentes: Bair, Blaszczyk, et al. 2018; Arthur 2018). Ahora bien, entre los estudiosos del pensamiento de Leibniz no hay unanimidad sobre varios aspectos del empleo de las ficciones en el período parisino. Hay al menos dos interrogantes significativos que guían los trabajos más recientes sobre esta cuestión:

- Es cierto que Leibniz empleó ficciones no solo en su pensamiento maduro, sino también en sus escritos de juventud; pero, ¿hay una continuidad entre la concepción y el empleo de ficciones en el pensamiento juvenil de Leibniz y el pensamiento maduro del autor? (Una 
visión 'continuista' es defendida en Arthur 2008 y 2009, mientras que Jesseph 2008 señala que, a pesar de que haya pasajes en los que Leibniz se refirió a ficciones en 1676, no es claro que haya sostenido consistentemente una posición ficcionalista en los escritos tempranos sobre el cálculo.)

- ¿Leibniz sostuvo una concepción de las cantidades ficticias en términos "sincategoremáticos" (es decir, como expresiones que designan cantidades finitas variables que pueden hacerse -según se trate de cantidades infinitamente pequeñas o infinitas- tan pequeñas $o$ tan grandes como queramos) o "categoremáticos" (esto es, como expresiones que designan cantidades fijas, con propiedades bien determinadas)? (La primera alternativa es defendida por Arthur 2013 y 2018, mientras que la segunda es sostenida por Katz y Sherry 2012 y 2013) No obstante, estos dos interrogantes esquivan, o al menos suponen resuelta, una cuestión más fundamental: para examinar si hay o no una continuidad entre las concepciones tempranas y maduras de Leibniz sobre las ficciones, o para ver cómo entiende estas cantidades, es decir, sincategoremática o categoremáticamente, debemos, primero, examinar qué es para Leibniz una ficción. Para orientarnos un poco en la concepción temprana de las ficciones de Leibniz, que, a su vez, nos permitirá dejar de manifiesto el camino que proponemos examinar en esta ocasión, consideremos un pasaje muy significativo en el que el autor considera esta cuestión, incluido en el tratado $D e$ quadratura arithmetica ( $A$ VII 6,520-676), que, por lo demás, es el texto más extenso de matemática infinita redactado por Leibniz en estos años:

A algunos les parecerán oscuras las cosas que hasta aquí hemos dicho sobre los infinitos y los infinitamente pequeños, como [parecen oscuras] todas las cosas nuevas. Pero con un poco de meditación, cada uno las percibirá fácilmente; quien en verdad las haya percibido, reconocerá el fruto. No importa si acaso tales cantidades existen en la naturaleza de las cosas; en efecto, alcanza con introducir una ficción, porque ofrecen compendios del hablar y del pensar, y por lo tanto del descubrir, del mismo modo que del demostrar, de manera que no sea siempre necesario hacer uso de [figuras] inscriptas o circunscriptas, llevar a cabo [deducciones] al absurdo ni mostrar que el error es menor que cualquiera asignable. Lo que consta que puede hacerse fácilmente, como dijimos a propósito de las proposiciones 6,7 y 8 . En efecto, [ante la cuestión de] si en verdad es posible que se exhiban demostraciones directas sobre estas cosas, me atrevería a afirmar que no pueden darse, a no ser que se admitan cantidad ficticias, infinitamente pequeñas o infinitas. Añádase [lo dicho] más arriba, prop. 7, escol. Por lo tanto, si en el futuro alguien se quejara del uso de estas cantidades, este se mostraría o ignorante o ingrato. 
Ignorante, a saber, si no entiende cuánta luz se enciende en todo el método de los indivisibles y en materia de las cuadraturas; pero ingrato, si disimula la utilidad que percibe. ( $A$ VII $6,585-586)^{1}$

De aquí podemos extraer algunas características de las cantidades ficticias. Por ejemplo, que la cuestión de su existencia no es algo que afecte a los geómetras, pues su interés está puesto en el uso y no en examinar cuestiones "ontológicas". Asimismo, en segundo lugar, que es necesario un rol activo del geómetra, en el sentido de que él las introduce. De esta manera, no son objetos que estén dados para los matemáticos, sino que, para poder usarlos, los matemáticos deben decidirse por suponerlos. En tercer lugar, también queda delimitado el ámbito de uso de las ficciones, pues señala que sirven no solamente para llevar a cabo demostraciones, sino también para el descubrimiento, así como también para hablar y pensar. Esto marca un panorama amplio y complejo del uso de ficciones. Ahora bien, hay una cosa más que Leibniz señala: las ficciones introducidas presentan abreviaturas o compendios de estos procesos, es decir, del hablar, pensar, descubrir y demostrar. El hecho de que sean "compendios" implica que son caracteres ( $A$ VI 3,433 ), por lo que encontramos una conexión entre el examen de las ficciones y la concepción leibniziana del conocimiento simbólico. Más aún, el hecho de que Leibniz señale que las ficciones son compendios, nos da una guía para examinar qué es una ficción. En este trabajo buscaré esquematizar el modo como Leibniz concibió los compendios en este período, con el objetivo de dilucidar la naturaleza simbólica de las ficciones. Esto me permitirá señalar, entre otras cosas:

- Que las ficciones son nociones ciegas, confusas, analógicas, creativas, cuyo empleo: se fundamenta en el hecho de que podemos sustituir los procesos en los que las utilizamos por otros ya conocidos que no las emplean; se orienta a la solución de problemas; y se sustenta en ciertas normas de operación que regulan su utilización.

- Que hay un complejo examen sobre el rol de las facultades cognitivas (pensamiento, imaginación, memoria, etc.) en el empleo de ficciones. Este aspecto es muy relevante, pues muestra que hay un trasfondo que oficia de marco teórico y conceptual sobre el cual Leibniz concibió las ficciones, por lo que las pocas afirmaciones que hizo sobre ellas parecen hallar una especie de justificación en el contexto de su sistema de pensamiento.

\footnotetext{
${ }^{1}$ Salvo que se indique lo contrario, las traducciones de este trabajo son mías.
} 
- Que Leibniz no introdujo la concepción de las ficciones ad hoc a raíz de las objeciones de Nieuwentijt al cálculo infinitesimal en 1694 o de Rolle a comienzos del siglo siguiente en la Academia de ciencias de París (Rolle 1703); por el contrario, pensó las ficciones en el marco del estudio del conocimiento simbólico, así como también de su utilidad y necesidad.

\section{Ideas, caracteres $y$ ficciones}

$\mathrm{Z}^{1}$ hecho de que las ficciones sean compendios exige tener en cuenta la distinción entre el proceso mediante caracteres y el proceso mediante ideas, que Leibniz concibió en el período parisino. La distinción entre estos dos procesos tiene varios aspectos, dado que los objetos con los que estamos tratando, es decir, ideas y caracteres, son de una naturaleza muy diferente. A continuación señalaremos algunas diferencias:

1. Mientras que los caracteres tienen una naturaleza simbólica, las ideas, o mejor dicho, las conexiones de las ideas, son pensamientos asimbólicos ( $A$ II 1,353). Leibniz dio una aproximación de lo que concibe por la noción de idea especialmente en algunos textos más bien tardíos del período parisino. Así, en De origine rerum ex formis de abril de 1676 señaló que "Idea es la diferencia de los pensamientos en razón del objeto" ( $A$ VI 3,518$)$. Una definición casi idéntica del mismo período se encuentra en una anotación de Leibniz redactada mientras leyó la Réponse pour la critique à la préface du second volume de la recherche de la vérité publicada en 1676 por Simon Foucher. En dicho texto, Foucher señaló que por "idea" entiende "todo lo que es la forma de alguna percepción" (Foucher 1679:30), a lo Leibniz añadió:"a la p. 30. Idea es aquello por lo que una percepción o pensamiento difiere de otro en razón del objeto" ( $A$ VI 3,314$)$. En otras palabras, una idea es una representación actual de un objeto y precisamente por ello las ideas son pensamientos que se diferencian entre sí en virtud de su contenido. Como vemos, esta concepción temprana de la noción de idea es diferente de la que explicitará en Quid sit idea de 1677, esto es, idea como facultad de pensar en la cosa, de acuerdo con lo cual "se dice que tenemos idea de una cosa aunque no estemos pensando en ella si podemos pensar en ella siempre que se presente la ocasión" ( $A$ VI 4, 1370; traducción de Leibniz 2003: 208).

2. Asimismo, dado que, tanto en los lenguajes naturales como en los artificiales, el recurso a una u otra notación es arbitraria, las ideas, en la medida en que no dependen de los símbolos, no están sujetas a la arbitrariedad, o bien, como dice Leibniz, "se presentan las mismas ideas para todos" ( $A$ II 1, 353; traducción de Leibniz 2014: 65). Ahora bien, por el lado del 
proceso por caracteres, Leibniz señala que un carácter se explicita en una definición, que luego, conectada con otras definiciones, compone una demostración. De esta manera, más allá de la explicitación, no hay una diferencia entre proceder por caracteres o por definiciones. En un escrito de finales de 1675 , en el que contempla varias de las cuestiones que examinaremos en este trabajo (De mente, de universo, de Deo, $A$ VI 3, 462), Leibniz piensa, a modo de ejemplo, que no hay una diferencia entre referirnos a "Dios" o a "aquello mayor que lo cual nada puede pensarse", pues la segunda formulación explica la primera.

3. Para Leibniz, tenemos ideas de cosas simples, pero de cosas compuestas tenemos solamente caracteres. El ejemplo que mencionamos antes pone de manifiesto esto: tenemos ideas de las cosas a las que se refieren las expresiones "aquello", "mayor", "nada", "pensarse", etc., pero no tenemos una idea de Dios como "aquello mayor que lo cual nada puede pensarse", sino solamente un carácter (es decir, el nombre "Dios") y la definición correspondiente. La expresión simbólica reunifica los pensamientos particulares, en el sentido de que, al pronunciar esa definición de Dios, no estamos pensando las palabras individuales por separado. En la definición, por lo tanto, conjugamos los vocablos o caracteres, aunque no las ideas ( $f f r$. Esquisabel 2012a: 5-6).

4. El proceso por caracteres permite fijar el pensamiento, de modo que, cuando es fijado en la materia, se hace visible tanto para nosotros como para otros. En cambio, el proceso por ideas pertenece exclusivamente al sujeto pensante. En este sentido, podríamos decir que la diferencia entre proceder mediante ideas y mediante caracteres equivale a diferenciar entre un proceso privado y uno público. La importancia del hecho de que los caracteres fijen el pensamiento radica especialmente en que esto permite no solo que el proceso de pensamiento sea percibido, sino que esto pueda hacerse en una mirada. Ahora bien, la fijación de los caracteres en la materia no es una condición necesaria del proceso por definiciones, en el sentido de que la captación simultánea de los caracteres que corresponden a las ideas singulares puede darse o bien en la sensación o bien en la imaginación. Si el número de caracteres no es muy grande, puede bastar con imaginarlos simultáneamente a todos. Si, por el contrario, el número de ellos es grande, es conveniente plasmarlos en la materia, con el objetivo de poder captarlos sensiblemente y, en consecuencia, estar seguros de que no nos hemos olvidado de nada.

El empleo de símbolos o caracteres admite una particularidad más. Leibniz reconoce que, en un gran número de ocasiones, procedemos solamente manipulando caracteres, es decir, sin tener en consideración directa las ideas mismas a las cuales se refieren. En buena medida, la importancia de proceder mediante caracteres radica precisamente en poder prescindir de 
considerar las ideas ( $A$ II 1,354; para ahondar en la concepción del conocimiento ciego, tanto en el período que aquí consideramos como en general en el pensamiento de Leibniz, véase Esquisabel 2012a y 2012b). Leibniz denomina ciegos a los pensamientos que proceden por medio de meros símbolos absteniéndose de la consideración de las ideas, precisamente por conducirse de este modo. De acuerdo con Leibniz, en los pensamientos ciegos se procede de manera análoga a como se procede en aquellos casos en los que se consideran unas pocas ideas comprendidas clara y distintamente. En este sentido, la utilidad del uso de símbolos descansa, en última instancia, en el carácter analógico del empleo de los símbolos, fundamentalmente en casos en los que se consideran simbólicamente cosas que son muy compuestas. En la tercera sección retomaremos la cuestión de la analogía en relación con el conocimiento simbólico.

La posibilidad de proceder por mera manipulación simbólica, sin atender a las ideas, es fundamental en el caso del empleo de cantidades ficticias. En primer lugar, las cantidades ficticias (como son, por ejemplo, una línea infinita terminada, una línea infinitamente pequeña terminada, el número infinito, etc.) son caracteres de cosas compuestas. En segundo lugar, porque, en consecuencia, de ellas no tenemos una idea singular. Así, Leibniz señala, a modo de ejemplo, que no hay una idea del número infinito ( $A$ VI 3 , 463). No obstante, si esto fuera todo, el uso de cantidades ficticias no tendría nada específico en relación con el proceso mediante caracteres en general, pues los vocablos, como por ejemplo "Dios", "círculo", y demás, son caracteres de cosas compuestas y por lo tanto no tenemos una idea de esas cosas. No obstante, Leibniz parece hacer una distinción entre dos problemáticas distintas:

- una cosa es que nosotros no tengamos ideas de cosas compuestas;

- otra cuestión es si esas ideas son o no posibles para alguna mente.

Como vemos, la primera de estas cuestiones trata de las capacidades cognitivas humanas, mientras que la segunda no tiene que ver con nuestras posibilidades, sino con ciertas notas de las ideas mismas. Así, por ejemplo, del hecho de que nosotros no tengamos una idea del círculo no se sigue necesariamente que ninguna mente pueda tenerla, ni tampoco, más en general, que dicha idea no sea posible. Incluso, para este ejemplo puntual, Leibniz señala que nosotros no tenemos una idea del círculo como tiene Dios ( $A$ VI 3, 463). En consecuencia, decir que la mente humana, por sus limitaciones, no puede tener una idea del círculo, no es lo mismo que decir que dicha idea no es posible. Esta distinción que aquí señalamos es muy importante al menos para dos de las cuestiones más significativas que Leibniz abordó en estos años, a saber: en primer lugar, para la reformulación del argumento ontológico, pues la estrategia de Leibniz es precisamente mostrar que, a pesar de que no ten- 
gamos una idea de Dios, su concepción no encierra una imposibilidad (para esto, véase Esquisabel y Gaiada 2019). En segundo lugar, para la cuestión de las ficciones. Como vimos, de las cantidades ficticias tenemos solamente caracteres, pero no tenemos una idea, pues dicha idea, si la hubiera, sería de una cosa compuesta. A esto hay que añadirle que, en este caso, la razón por la que no tenemos una idea no tiene que ver exclusivamente con una limitación de nuestras capacidades cognitivas, sino también con el hecho de que estas cantidades encierran una imposibilidad. En este sentido, la cuestión no es solo que nosotros carezcamos de una idea de estas cosas, sino también que de hecho no hay en absoluto una idea de ellas. En el diálogo Pacidius Philalethi, Leibniz extrajo algunas conclusiones en esta línea cuando examina la cuestión del número infinito:

- la noción del "número infinito" implica una contradicción (no me detendré en esta cuestión, que examinamos en detalle en Esquisabel y Raffo Quintana 2017);

- lo que tiene consecuencias contradictorias es imposible;

- esto implica que ni siquiera Dios entiende el número de todas las unidades, pues, como le indica Pacidio a Teófilo en el diálogo, “¿De qué modo afirmas que entiende lo que es imposible?” ( $A$ VI 3,552$)$. Ahora bien, a pesar de que, en el caso del número infinito, la imposibilidad se da por implicar una contradicción, Leibniz entiende que la primera de estas nociones es más amplia que la segunda. En otras palabras, para el filósofo de Leipzig la noción de imposibilidad es doble: por un lado, cuando nos referimos a aquello que no tiene esencia, es decir, lo que implicaría una contradicción, y por otro, cuando nos referimos a algo que no tiene existencia, es decir, a lo que es incompatible con Dios ( $A$ VI 3,463 ). Si bien el número infinito es imposible en el primer sentido, no es claro que todas las cantidades ficticias lo sean. Por ejemplo, en el caso de las cantidades infinitamente pequeñas, Leibniz parece concebir al menos el segundo tipo de imposibilidad: como para cualquier cosa podemos encontrar otra más pequeña al infinito, no habría razón para que el infinito sea terminado, de modo que haya una cosa más pequeña que la cual no habría otra ( $A$ VI $3,564-565)$. En otras palabras: como Dios no hace nada sin razón, una cantidad infinitamente pequeña sería incompatible con él. Podríamos pensar que una línea infinita terminada es imposible por una razón análoga: tal línea sería incompatible con Dios porque no tendría razón para admitir un punto final y no otro. No obstante, como dijimos, no es claro si Leibniz concibe que estas nociones impliquen una contradicción o no.

Estas son, en síntesis, las razones por las que decimos que las ficciones son nociones ciegas, pues, a saber, procedemos sin considerar las ideas, en este caso porque de hecho no hay una idea que les corresponda, pues implican 
una imposibilidad. De esta manera, de algún modo son también nociones confusas, dado que hay un conocimiento vago del significado de los caracteres correspondientes ( $c f r$. Esquisabel 2012a: 7).

\section{Exhibición conjunta y simultánea}

A ntes señalamos a la pasada que una expresión simbólica reunifica Anominalmente pensamientos singulares, en el sentido de que los representa de manera conjunta, lo que hace que el pensamiento sea accesible en una mirada. Esto es muy significativo, en especial, en caso de que estemos tratando de ideas de cosas compuestas, esto es, para las que no hay de hecho una idea. Así, los compendios nos permiten exhibir, con cierta unidad, cosas que no estén unidas por sí ( $A$ VI 3,503$)$. En este sentido, hay una unidad mental, provista, en el caso del uso de caracteres, por el hecho de tener nombres (como "Dios") que se refieren, de un modo unitario, a los agregados de cosas ("aquello mayor que lo cual nada puede pensarse"). Este hecho deja en evidencia que para Leibniz las palabras tienen una función unitiva desde el punto de vista de nuestra comprensión de las cosas. En otras palabras, en estos casos hay una unidad nominal. Leibniz ya había expuesto buena parte de esta visión en la Dissertatio de Arte Combinatoria de 1666. Al comienzo de este texto, señala que podemos considerar en simultáneo cuantas cosas queramos y suponerlas como un todo. Si concebimos que hay algo en común entre muchas cosas, de manera que podamos tomarlas como partes de un todo, entonces inventamos un nombre para referirnos de manera unitaria al agregado de dichas cosas, evitando así tener que nombrarlas una por una y, en consecuencia, abreviando el discurso de manera significativa. No es que conozcamos un todo (pues se trata de cosas agregadas), sino que empleamos un nombre que es tomado como si fuera un todo $(A$ VI 1,169; ffr. Esquisabel 2012a: 12-13).

No obstante, no hay que perder de vista que la unidad mental no es provista únicamente por la palabra hablada o escrita, sino que es, más en general, una característica del pensamiento simbólico en general. Esto se ve también en el empleo de imágenes, sean, en este caso, mentales o diagramas en la materia. La relación entre el proceso por ideas y el proceso por caracteres es análoga a la que hay entre proceder por simples imágenes mentales (simplices imaginationes) y proceder mediante dibujos o diagramas fisicos (delineationes). La diferencia entre los analogados en parte está relacionada con la facultad epistémica con la que se relacionan, pues las imágenes estimulan los sentidos, mientras que los caracteres, el pensamiento ( $A$ VI 3, 463). Ahora bien, el límite de la analogía entre proceder por ideas y proceder 
por imágenes mentales parece ser que, mientras que las ideas pensadas son simples (pues no tenemos ideas de cosas compuestas), las imágenes mentales no lo son necesariamente, en el sentido de que podemos imaginarnos cosas cuyas ideas, si las tuviéramos, serían de cosas compuestas, como, por ejemplo, cuando nos imaginamos un círculo. Como señalamos antes, Leibniz entiende que la idea del círculo sería una idea de una cosa compuesta, de modo que no tenemos nosotros una idea suya como tiene Dios, "quien piensa simultáneamente todas las cosas" ( $A$ VI 3, 463). A pesar de que no tengamos una idea única del círculo, disponemos de una imagen mental del círculo, así como también de una definición de esta figura, y, por lo tanto, de las ideas de las cosas singulares cuyos caracteres combinamos para elaborar su definición: "Pensamos acerca del círculo, demostramos sobre el círculo, conocemos el círculo: tenemos su esencia pensada; pero por partes. Si pensáramos simultáneamente toda la esencia del círculo, tendríamos la idea del círculo" ( $A$ VI 3 , 463). En consecuencia, la unidad es provista por la mente, o bien mediante una definición o bien mediante una imagen:

La falta de la idea en nosotros es suplida por una imagen sensible o una definición, es decir, el agregado de caracteres, en los que no se requiere semejanza alguna. El lugar de la idea lo ocupa siempre una manifestación figurativa que se percibe de una sola vez como un todo. Las imágenes excitan los sentidos y los caracteres, el pensamiento: las primeras son más aptas para las operaciones, mientras que los segundos lo son para el razonamiento. ( $A \mathrm{VI}$ 3, 463; traducción de Oscar Esquisabel)

Así, la ausencia de una idea de una cosa compuesta es suplida por algo que nos permita captar tout d'un coup todo lo que esta figura implica, esto es, o bien una definición, con la que tenemos simultáneamente todos los caracteres de las ideas involucradas, o bien una imagen, que es sentida toda simultáneamente.

\section{Naturaleza analógica de los caracteres}

T a analogía es un elemento clave para entender una característica

Lsignificativa del conocimiento simbólico en general. Recordemos que para Leibniz tenemos ideas solamente de cosas simples, de modo que, cuando utilizamos vocablos de cosas compuestas, procedemos por analogía, es decir, como si tuviéramos una idea correspondiente, a pesar de que esto no sea posible para nuestro entendimiento. En este sentido, hay que ser precavidos y no olvidarse de que no tenemos ideas de cosas compuestas. La 
unidad nominal a la que nos referimos en la sección anterior no implica que tengamos una idea unitaria a la que ella se refiera. Simplemente nos imaginamos que tenemos una idea correspondiente, es decir, una idea "como si" pensáramos simultáneamente todas las ideas, que, repetimos, solo podemos pensar por separado. Leibniz dice al respecto, reflexionando sobre el argumento ontológico:

No es que una las ideas de estas cosas entre sí, sino que inmediatamente después uno solo las palabras, es decir, los caracteres y me imagino que tengo la idea de algo tal que no puede pensarse algo mayor, a saber, como si pensase todas estas cosas a la vez.Y en esto engañamos a los otros y a nosotros mismos; y aquí está el origen del error acerca de las ideas. Tenemos ideas de cosas simples, pero solo tenemos caracteres de las cosas compuestas. Ahora bien, si pudiésemos abarcar con un único pensamiento aquello tal que no puede pensarse algo mayor, tendríamos la idea de un máximo. Y si pudiésemos pensar aquello tal que no puede pensarse algo más poderoso, tendríamos la idea de lo máximamente poderoso; asimismo, si [pudiésemos pensar] aquello tal que no pudiese pensarse algo más bello, tendríamos la idea de lo perfecto. ( $A$ VI 3, 462; traducción de Oscar Esquisabel)

Ahora bien, en el caso de las ficciones, el carácter analógico se vuelve aún más significativo. Tengamos en cuenta este ejemplo de Leibniz: "Como cuando digo que $\sqrt{ }(-1)$ es una cantidad posible, procedo por ciertas analogías" ( $A$ VI 3,462 ). Como toda raíz cuadrada es de números positivos, las raíces cuadradas de números negativos (es decir, los números imaginarios), no son cantidades posibles. De esta manera, podemos calcular utilizando raíces imaginarias, no porque sean cantidades posibles, pues no lo son. No obstante, procedemos por analogía, tomándolas como si fueran posibles. Leibniz era consciente de que no fue el primero en concebir que pueden obtenerse resultados correctos "[...] aun admitiendo cosas imposibles, como son dimensiones que sobrepasan la tercera [dimensión], los números sordos y los menores que cero" ( $A$ II 1, 354; traducción de Leibniz 2014: 66). Un caso históricamente relevante del ejemplo que Leibniz menciona aquí es el empleo precisamente de raíces imaginarias que hizo Cardano en su Ars Magna de 1545. Un poco más tarde, Bombelli operó también con cosas imaginarias en su Algebra de 1572, obra que Leibniz conocía (sobre esta cuestión, Katz y Sherry 2012: 168-171). De esta manera, el ejemplo de las raíces imaginarias muestra la potencia del razonamiento por analogía, pues, en el caso de la matemática, permite introducir ficciones que no son ni siquiera posibles (Esquisabel 2008: 7-8). Basta con que los tomemos, por analogía, como si lo fueran. 
La situación no es distinta en el caso de las cantidades ficticias infinitas e infinitamente pequeñas. Conjugamos los vocablos "número" e "infinito", y operamos como si hubiera una idea que le corresponda, es decir, como si fuera una cantidad, aunque no lo sea, o como si fuera un número, aunque no lo haya, pues, recordemos, estas cantidades implican una imposibilidad. La ficción se da por suponer que son cantidades infinitas terminadas. Leibniz explícitamente conjuga las expresiones "infinito" y "terminado" cuando define al infinito como una cantidad, sea terminada o interminada, mayor que la que podamos entender, es decir, mayor que cualquiera asignable por nosotros o designable por números ( $A$ VII 6,549 ). Así, por ejemplo, una línea infinita interminada es aquella para la cual no hay un último punto, por lo menos por uno de sus lados, mientras que una línea infinita terminada es aquella para la cual hay un último punto ( $A$ VI 3,485$)$. Ahora bien, el hecho de que demos una definición de una cantidad infinita terminada no significa que haya una tal cantidad. Aquí se observa nuevamente lo que llamamos el aspecto creativo de las cantidades ficticias, es decir, el hecho de que su introducción implique un rol activo -creativo- de los geómetras.

La utilidad que tiene esta introducción puede verse, por ejemplo, en el campo de la aritmética de los infinitos. En una suma infinita, no es necesario que sumemos uno por uno los términos singulares, pues basta con compendiar estas operaciones de la mente, de manera que tomamos la suma como una totalidad terminada:

[...] y por lo tanto, todo el mérito de las ciencias abstractas consiste en conocer compendios del hablar y del escribir; y su conocimiento hace que podamos computar el término y la suma de alguna progresión, tout d'un coup, aunque no pasemos por los singulares, de modo que podamos exhibir algo finito igual a lo infinito mismo. ( $A$ VI 3,456$)$

La posibilidad de computar la suma de un golpe implica suponer que está dada la totalidad de la progresión, es decir, las infinitas fracciones, a pesar de que el infinito no sea un todo; procedemos por analogía, como si lo fuera. Una serie infinita no tiene un último término, por lo que presuponerla en su totalidad, con un número infinito determinado de términos, implica introducir una ficción. Esta concepción le dio grandes resultados a Leibniz, como, por ejemplo, en su propuesta de una cuadratura aritmética del círculo. En el Praefatio opusculi de Quadratura Circuli Arithmetica, Leibniz señala:

[...] si el cuadrado del diámetro es 1 , el círculo se iguala a la totalidad de la progresión de las fracciones que tienen a la unidad como numerador y a los impares como denominador alternativamente afirmadas y negadas, a saber, 
$\frac{1}{1}-\frac{1}{3}+\frac{1}{5}-\frac{1}{7}+\frac{1}{9}-\frac{1}{11}$ etc. al infinito, como se demostrará en este opúsculo; de allí que no puede negarse que se ha encontrado un valor exacto del círculo y una expresión de su magnitud completamente verdadera. ( $A$ VII 6,174; las cursivas son mías; traducción de Leibniz 2019: 67-68)

Ahora bien, suponer la totalidad de la progresión no implica que, filosóficamente hablando, la serie tenga un número infinito de términos, porque tal número no existe. Aquí se observa, nuevamente, el aspecto creativo del uso de ficciones:

Debe examinarse aún si esto es verdadero y en qué medida lo es, a saber, que el cuadrado es al círculo como 1 a $\frac{1}{1}-\frac{1}{3}+\frac{1}{5}-\frac{1}{7}+\frac{1}{9}-\frac{1}{11}$ etc. Pues cuando decimos etc. al infinito, entendemos que el último número sin duda no es el máximo entre los números, pues este no existe, pero sin embargo es infinito. Pero, ¿acaso [la serie] no está determinada de algún modo? En efecto, debe añadirse algo, aunque se suponga un número infinito, por lo que debe decirse que esto no es rigurosamente verdadero. ( $A$ VI 3, 502; traducción de Leibniz 2019: 54-55)

El razonamiento es interesante: el hecho de que la razón del cuadrado al círculo sea como la de la unidad a la serie de Leibniz, es una conclusión filosóficamente problemática, pues no hay nada a lo que se refiera realmente la expresión "número infinito", es decir, es un pensamiento ciego que no tiene una idea a la que pudiera ser referido. No obstante, desde el punto de vista del cálculo, esto es irrelevante. Lo importante parece ser, más bien, que la serie infinita contiene no solamente la posibilidad de aproximarnos más y más a un valor exacto, sino también "una verdadera y exacta igualdad" ( $A$ VII 6, 439).

\section{Cuestiones de fundamentos}

T a posibilidad de proceder mediante el uso de cantidades ficticias

Ldeja lugar a algunos interrogantes sobre la validez de un procedimiento de este tipo. En efecto, ¿cómo garantizar el correcto funcionamiento de un proceso que utiliza cantidades que no son posibles? Hay por lo menos tres cuestiones sobre los fundamentos del empleo de ficciones que deben considerarse:

1. ¿Qué justifica o valida que podamos utilizar cantidades ficticias?

2. ¿Por qué utilizar ficciones, si podemos no introducirlas?

3. ¿Hay reglas de operación que estipulan el uso de ficciones? 
En esta sección mostraremos que podemos extraer posibles respuestas de Leibniz a estas cuestiones a partir de los textos del período parisino. Nos centraremos, en especial, en las primeras dos cuestiones, dejando de lado la tercera, puesto que la presencia de reglas de operaciones con infinitos e infinitamente pequeños en el período parisino está ya suficientemente documentada, en especial gracias a los trabajos de E. Knobloch, que ha detectado doce reglas y ha mostrado algunos ejemplos de su utilización (véase, por ejemplo, Knobloch 1990: 45-47; 1994: 272-273; 2002: 67-68).

En buena medida, la respuesta a las primeras cuestiones quedó sucintamente esbozada a la pasada en algunos momentos de este trabajo: podemos proceder utilizando un método que emplee ficciones porque es posible reemplazar ese método por otro que no las utilice. En De quadratura arithmetica, Leibniz señala el beneficio que tiene la utilización de cantidades ficticias para la demostración de teoremas de cuadraturas. Esta aclaración tiene lugar luego de haber presentado las bases fundamentales de su método infinitesimal, que permite proveer resultados para cuadraturas sin necesidad de recurrir a una doble reducción al absurdo, de manera que, en consecuencia, no es necesario inscribir y circunscribir figuras (como se obtiene empleando en método de exhaución de Arquímedes). En el escolio de la séptima proposición, en la que ejemplifica la aplicación de su método mediante la cuadratura de una curva cualquiera, Leibniz señala:

Confieso, ciertamente, que no he conocido hasta ahora un camino por el que pueda demostrarse perfectamente ni una única cuadratura sin una deducción al absurdo; tengo incluso razones para dudar de que esto pueda hacerse mediante la naturaleza de las cosas, sin suponer cantidades ficticias, a saber, infinitas o infinitamente pequeñas. Sin embargo, de todas las deducciones al absurdo, creo que ninguna es más simple y natural, y cercana a una demostración directa, que la que muestra no solo simplemente que entre dos cantidades no hay ninguna diferencia, y por ello que son iguales (pues, por lo demás, suele probarse mediante un razonamiento doble que una no es ni mayor ni menor que otra), sino también que la que emplea solamente un término medio, a saber, inscrito-circunscrito, pero no simultáneamente ambos.Y da como resultado que tengamos comprensiones más claras de estas cuestiones. (AVII 6, 537)

De alguna manera, Leibniz establece una especie de jerarquía de demostraciones teniendo como criterio la simplicidad de la prueba. En otras palabras, hay que distinguir, en materia de cuadraturas, entre:

- Las demostraciones que proceden por doble reducción al absurdo;

- Las demostraciones apagógicas que apelan a una única reducción al absurdo; 
- Las demostraciones directas, sin reducción al absurdo, las cuales no pueden llevarse a cabo sin cantidades ficticias.

De esta manera, este pasaje pone de manifiesto uno de los rasgos más destacados del empleo de ficciones de Leibniz: su uso nos provee de un procedimiento más simple que el que emplearíamos si no las utilizáramos. Sin la introducción de ficciones, podemos dar, en el mejor de los casos, demostraciones en materia de cuadraturas que no recurran a figuras inscritas y circunscritas, sino a "algo intermedio", inscrito-circunscrito, de manera que no se recurra a una doble reducción al absurdo, sino a una única reducción (que es lo que Leibniz propone en las primeras proposiciones). Solamente asumiendo cantidades ficticias podría darse una demostración directa, que, de darse, es preferible por su simplicidad. De esta manera, Leibniz podría haber respondido a los dos interrogantes que señalamos antes de este modo:

1. La utilización de un método que emplee cantidades ficticias queda validada por el hecho de que podemos reemplazarlo por otro que no las utilice;

2. Es conveniente utilizarlas porque su uso nos provee de un proceso más sencillo.

Notemos que las respuestas son solidarias entre sí: si se prefiriera utilizar un procedimiento que no emplee ficciones, deberíamos sacrificar, al menos en parte, la simplicidad del método. Ahora bien, la distinción entre una demostración apagógica (sea de doble o de simple reducción al absurdo) y una demostración directa, implica, a su vez, la diferencia entre un proceso que nos provee de resultados siempre aproximados y un proceso que puede proveernos de resultados exactos.

En los exámenes de Leibniz sobre el problema de la cuadratura del círculo, se observa claramente este aspecto de su método. No es mi intención aquí centrarme en el resultado de Leibniz en materia de cuadraturas (he tratado esta cuestión el Raffo Quintana 2018 y en un trabajo en prensa; asimismo, véase Crippa 2019: 93-156). Tengamos en cuenta solamente que Leibniz propuso una cuadratura aritmética, es decir, mediante series infinitas de números racionales. Leibniz considera que el resultado que él ofrece es novedoso, en buena medida, porque hasta el momento solamente se habían dado aproximaciones, es decir, que "nadie dio una progresión de números racionales cuya suma, continuada al infinito, sea exactamente igual al Círculo", mientras que él ofreció "una Serie de Números racionales muy simple, cuya Suma se iguala exactamente a la Circunferencia del Círculo, supuesto que el Diámetro es la Unidad" (GM I, 55). Tenemos, entonces, las dos características que señalamos: la serie que él provee es más simple y su resultado no es aproximado, sino exacto. La conexión entre esta cuestión y lo que señalamos en las secciones anteriores es evidente: para dar un resultado exacto, debemos presuponer que la serie se da de manera completa. 


\section{Conclusiones}

$\mathrm{Z}^{1}$ hecho de tomar la concepción leibniziana del conocimiento

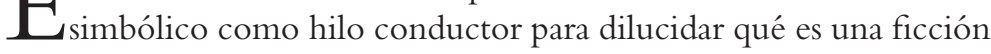
parece aportar conclusiones importantes. Como vimos, en el período parisino Leibniz concibió las ficciones como nociones ciegas, en la medida en que no refieren a ideas, no solo porque no está en nuestras capacidades tener ideas de cosas compuestas, sino también, y especialmente, porque no hay ideas que les correspondan, puesto que estas nociones encierran una imposibilidad. Asimismo, entendió que las ficciones comportan un carácter analógico, en el sentido de que, a pesar de que no sean cantidades posibles, operamos con ellas como si lo fueran. De esta manera, si bien el infinito no es un todo, suponemos que se da una totalidad infinita como si esto fuera posible, empleando expresiones como "número infinito" o "línea infinita terminada". Si bien estas cantidades no son posibles, la posibilidad de sustituir los procedimientos en los que empleamos estas ficciones por otros que no las utilizan de alguna manera justifica su utilización.

Para finalizar, quisiera hacer una observación relacionada con el primero de los interrogantes que, según señalé en la introducción, guían buena parte de los trabajos recientes sobre las ficciones, a saber, si hay o no una continuidad entre las concepciones de las ficciones de juventud y de madurez del filósofo de Lepizig. Como veremos, hay indicios para argumentar a favor de una lectura continuista. Por ejemplo, hay una admirable concordancia entre la visión del período parisino y la concepción que esbozó treinta años más tarde en la correspondencia con Des Bosses a raíz de los reparos que este pensador puso a la concepción del infinito actual de Leibniz. Para aclarar su concepción, en una carta del 7 de marzo de 1706 (GP II, 304-308), Leibniz esboza una serie de aclaraciones utilizando, como ejemplo, dos casos que ya encontramos en el período parisino, a saber, el del número infinito y el de una línea infinita terminada. Allí señala que, cuando empleamos estas locuciones, si quisiéramos ser realmente más precisos, en lugar de "número infinito", deberíamos decir que hay más cosas que las que pueda expresarse con número alguno, del mismo modo que, en lugar de "línea recta infinita", habría que decir que la recta producida es de una magnitud mayor que cualquiera asignable, de modo que siempre haya una recta mayor. En otras palabras, "Es esencial al número, a una línea o a cualquier todo, ser terminado" (GP II, 304). En consecuencia, concebimos por analogía un número infinito terminado o una línea infinita terminada, como si se tratase de totalidades, no porque lo sean, sino porque introducimos una ficción: "Hay, por lo tanto, un compendio del hablar cuando decimos 'uno' donde hay más cosas que las que pueden ser comprendidas en un todo asignable, y expresamos a la manera de 
una magnitud lo que no tiene sus propiedades" (GP II, 305). En este sentido, la unidad que proveen es verbal (neque adeo nisi verbalem haberet unitatem). Notemos, por lo demás, que la última parte de la última cita marca el límite de la analogía: el número infinito no es ni par ni impar, a pesar de que sea una propiedad de cualquier número ser o par o impar, del mismo modo que de una línea infinita no podemos decir si es conmensurable con otra recta dada, a pesar de que sea una propiedad de toda recta ser conmensurable con otra," de modo que solo impropiamente estas son locuciones sobre el infinito como una magnitud, fundadas en alguna analogía; pero estas, examinadas más minuciosamente, no pueden sostenerse" (GP II, 305). De allí que, sobre las cantidades ficticias infinitas e infinitamente pequeñas, Leibniz dice cosas muy semejantes a lo que vimos anteriormente:

Filosóficamente hablando, yo no afirmo más las magnitudes infinitamente pequeñas que las infinitamente grandes, es decir, no más las infinitésimas que las infinituplas. En efecto, para decirlo abreviadamente, las tengo a ambas por ficciones de la mente, aptas para el cálculo, como también son las raíces imaginarias en el Álgebra. Entretanto, demostré que estas expresiones tienen un gran uso para compendiar el pensamiento y por ello para la invención, y no pueden conducir al error, pues basta que sustituya, por lo infinitamente pequeño, algo tan pequeño como se quiera, de modo que el error sea menor que uno dado, de donde se sigue que no puede darse un error. (GP II, 305)

Notemos que, hacia el final del pasaje, Leibniz señala que la sustituibilidad por otras expresiones que no refieren a cantidades ficticias es lo que, en última instancia, da garantías de que no concluyamos errores cuando operamos con ficciones. En este caso, parece haber una diferencia en relación con lo que señaló en el período parisino, pues, en ese momento, Leibniz concibió la sustituibilidad de los métodos y no de las expresiones. Es posible que ambas cosas estén indisociablemente ligadas, pues, al sustituir un proceso que utilice ficciones por otro que no lo haga, debemos reemplazar las expresiones que refieran a ficciones. Sea como fuere, lo que aquí señalamos basta para mostrar que hay, al menos, un claro indicio a favor de una lectura continuista. ${ }^{2}$

\footnotetext{
${ }^{2}$ Este trabajo fue realizado en el marco de los proyectos "La Ciencia General de Leibniz como fundamentación de las ciencias: lógica, ontología y filosofía natural” (ANPCyT PICT-2017-0506) y "Resultados de imposibilidad en geometría: perspectivas históricas y semánticas” (ANPCyT PICT-2017-0443).
} 


\section{BIBLIOGRAFÍA}

Arthur, R. T. W. (2008), "Leery Bedfellows: Newton and Leibniz on the Status of Infinitesimals", en D. Jesseph y U. Goldenbaum (2008) (eds.), Infinitesimal Differences: Controversies between Leibniz and his Contemporaries (Berlin - New York: Walter de Gruyter, 7-30)

Arthur, R. T. W. (2009), "Actual Infinitesimals in Leibniz's Early Thought", en M. Kulstad, M. Laerke y D. Snyder (2009) (eds.), The Philosophy of the Young Leibniz (Stuttgart: Franz Steiner, 11-28).

Arthur, R. T. W. (2013), "Leibniz's Syncategorematic Infinitesimals", Archive for History of Exact Sciences, 67: 553-593

Arthur, R. T. W. (2018), "Leibniz's Syncategorematic Actual Infinite", en O. Nachtomy y R. Winegar (2018) (eds.), Infinity in Early Modern Philosophy (Cham: Springer, 155-179).

Bair, J., Blaszczyk, P. et al. (2018), "Leibniz's Well-Founded Fictions and their Interpretations", Matematchni Studii, 49 (2): 186-224.

Crippa, D. (2019), The Impossibility of Squaring the Circle in the $17^{\text {th }}$ Century: a Debate among Gregory, Huygens and Leibniz (Cham: Birkhäuser).

Esquisabel, O. M. (2008), "Leibniz y el concepto de analogía”, Revista de Filosofía y Teoría Política, 39: 11-29.

Esquisabel, O. M. (2012a), "Representing and Abstracting: an analysis of Leibniz's Concept of Symbolic Knowledge”, en A. Lassalle Casanave (2012) (comp.), Symbolic Knowledge from Leibniz to Husserl (College Publications: Londres, 1-49).

Esquisabel, O. M. (2012b), "Leibniz: las bases semióticas de la characteristica universalis", Representaciones, 8 (1): 5-32.

Esquisabel O. M. y Gaiada, G. (2019), "La reformulación leibniziana del argumento ontológico: de la certeza a la probabilidad”, O que Nos Faz Pensar, 44 (28): 218-238.

Esquisabel, O. M. y Raffo Quintana, F. (2017), "Leibniz in Paris: a Discussion Concerning the Infinite Number of All Units", Revista Portuguesa de Filosofia, 73 (3-4): 1319-1342.

Foucher, S. (1676), Réponse pour la critique à la préface du second volume de la recherche de la vérité (Paris: Robert J. B. de la Cailles, 1679).

Gavroglu, K., Christianidis, J. y Nicolaidis, E. (1994) (eds.), Trends in the historiography of science (Dordrecht - Boston - London: Kluwer Academic Publishers).

Jesseph, D. (2008), "Truth in Fiction: Origins and Consequences of Leibniz's Doctrine of Infinitesimal Magnitudes”, en D. Jesseph y U. Goldenbaum (2008) (eds.), Infinitesimal Differences: Controversies between Leibniz and his Contemporaries (Berlin - New York: Walter de Gruyter, 215-233).

Jesseph, D. y Goldenbaum, U. (2008) (eds.), Infinitesimal Differences: Controversies between Leibniz and his Contemporaries (Berlin - New York: Walter de Gruyter).

Katz, M. y Sherry, D. (2012), "Infinitesimals, Imaginaries, Ideals, and Fictions”, Studia Leibnitiana, 44 (2): 166-192. 
Katz, M. y Sherry, D. (2013), "Leibniz's Infinitesimals: their Fictionality, their Modern Implementations, and their Foes from Berkeley to Russell and beyond", Erkenntnis, 78 (3): 571-625.

Knobloch, E. (1990), “L'infini dans les matématiques de Leibniz”, en A. Lamarra, (1990) (ed.), L' infinito in Leibniz: problemi e terminologia: Simposio internazionale del Lessico intellettuale europeo e della Gottfried-Wilhelm-Leibniz-Gesellschaft: Roma, 6-8 novembre 1986 (Roma: Edizioni dell'Ateneo, 33-51).

Knobloch, E. (1994): “The Infinite in Leibniz's Mathematics - the Historiographical Method of Comprehension in Context", en K. Gavroglu, J. Christianidis y E. Nicolaidis (1994) (eds.), Trends in the historiography of science (Dordrecht - Boston - London : Kluwer Academic Publishers, 265-278).

Knobloch, E. (2002): “Leibniz's Rigorous Foundation of Infinitesimal Geometry by Means of Riemannian Sums", Synthese, 133: 59-73.

Kulstad, M., Laerke, M. y Snyder, D. (2009) (eds.), The Philosophy of the Young Leibniz (Stuttgart: Franz Steiner).

Lamarra, A. (1990) (ed.), L' infinito in Leibniz: problemi e terminologia: Simposio internazionale del Lessico intellettuale europeo e della Gottfried-Wilhelm-Leibniz-Gesellschaft: Roma, 6-8 novembre 1986 (Roma: Edizioni dell'Ateneo).

Lassalle Casanave, A. (2012) (comp.), Symbolic Knowledge from Leibniz to Husserl (College Publications: Londres).

Leibniz, G. W. $(A)$, Sämtliche Schriften und Briefe, ed. Deutsche Akademie der Wissenschaften (Darmstadt - Leipzig - Berlin: Akademie-Verlag, 1923 y ss.) (citado indicando la serie (en números romanos), el tomo (en números arábigos) y número de página).

Leibniz, G. W. (GM), Die Mathematischen Schriften, ed. C. I. Gerhardt (Berlin - La Haya: A. Ascher \& Comp - H.W. Schmidt, 1849-1863) (citado indicando número de volumen (en números romanos) y número de página).

Leibniz, G. W. (GP), Die Philosophischen Schriften, ed. C. I. Gerhardt (Berlin:Weidmann, 1875-1890) (citado indicando número de volumen (en números romanos) y número de página).

Leibniz, G. W. (2003), Escritos filosóficos, edición de E. de Olaso, notas de E. de Olaso y R. Torretti, traducciones de R. Torretti, T. E. Zwanck y E. de Olaso (Madrid: A. Machado)

Leibniz, G. W. (2014), "Introducción a la aritmética de los infinitos (1672)", traducción del latín e introducción de F. Raffo Quintana, Notae Philosophicae Scientiae Formalis, 3: 47-69.

Leibniz, G. W. (2019), Sobre los infinitos, prólogo, selección, traducción y notas de O. Esquisabel y F. Raffo Quintana (Buenos Aires: Excursus-CIF).

Nachtomy, O. y Winegar, R. (2018) (eds.), Infinity in Early Modern Philosophy (Cham: Springer).

Nieuwentijt, B. (1694): Considerationes circa analyseos ad quantitates infinite parvas appli- 
catae principia, et calculi differentialis usum in resolvendis problematis Geometricis (Amsterdam:Wolters).

Raffo Quintana, F. (2018), "Leibniz on the Requisites of an Exact Arithmetical Quadrature", Studies in History and Philosophy of Science, 67: 65-73.

Raffo Quintana, F. (en prensa), "La visión de Leibniz sobre el producto infinito de Wallis”, aceptado para su publicación en el número temático sobre Leibniz de la revista Tópicos.

Rolle, M. (1703), "Du nouveau système de l'infini", Memoires de mathématique et de physique de l'Académie royale des sciences (Académie royale des sciences: 312-336).

Recibido: 17-07-2019; aceptado: 02-10-2019 